\title{
The Hypothetical Learning Trajectory on Addition in Mathematics GASING
}

\author{
Rully Charitas Indra Prahmana \\ Department of Mathematics Education, Surya College of Education, Tangerang, Indonesia \\ $<$ rully.charitas@stkipsurya.ac.id>
}

\begin{abstract}
The purpose of this study is to look at the role of using Mathematics GASING (Math GASING) to help students understand and master the addition concept from the informal level (concrete) to the formal level. The research method used is design research with a preliminary design, teaching experiments, and retrospective analysis stages. This study describes how the Math GASING made a real contribution for students understanding of the concept of addition. The whole strategy and model that requires students to discover, to describe, and to discuss during the construction phase demonstrates how students can use their initial understanding of the addition concept. The stages in the learning trajectory have an important role in understanding the addition concept from informal level to formal level and also make the study of mathematics more easy, fun, and enjoyable.
\end{abstract}

Keywords: addition, learning trajectory, design research, Math GASING

\section{Introduction}

Professional teachers, as the product of reform in education, must have higher education qualifications and be able to innovate in teaching and learning (Prahmana, 2013). So, every prospective teacher should be prepared to become a professional teacher to equip himself through higher education and knowledge of the learning and teaching process. For example knowledge of using a spreadsheet, such as Microsoft Excel, can provide educators with a creative tool for the study and teaching of mathematics, mathematical modelling, and mathematical visualization where Excel's graphics can create eye-catching animated graphic displays and inject more fun into the study of mathematics (Arganbright, 2007).

However prospective teachers who come from rural areas have a little access to a decent education and sufficient information required to become professional teachers. Surya College of Education has a responsibility to help these prospective teachers to get a good education to become professional mathematics teachers. In support, Surya and Moss (2012) have created and applied a learning innovation in mathematics education named Mathematics GASING (Math GASING).

Learning number operations at the primary school is important for learning other subjects because it helps them to understand notation, symbols, and other forms to represent (reference numbers), and it can support the students' thinking and understanding to solve problems 
National Council of teachers of Mathematics (NCTM), 2000). The results of several previous studies show that students have difficulty in understanding number operations (Prahmana, 2013; Prahmana, Zulkardi, \& Hartono, 2012). Initial results conducted by researchers in pre-test of classroom observations of rural area students, from Ambon, Serui, and Sorong Selatan towards learning number operations. I found that students were more likely to be introduced through the use of the formula without involving the concept itself and learning number operations separate from any concrete experience. Research shows the addition operation is a number operation which first must be mastered before a student learns another number operation (Reys, Suydam, Lindquist, \& Smith, 1984). This challenged the researcher to try designing the addition operation learning sequence in Math GASING which always starts from the concrete (informal level) and progressing to the abstract (formal level) for matriculation prospective teachers students at Surya College of Education Tangerang who are recruited from Ambon, Serui, Yapen, and South Sorong, Papua.

\section{Math GASING}

Surya and Moss (2012) stated that GASING has four basic premises. First, there is no such thing as a child that cannot learn mathematics, only children that have not had the opportunity to learn mathematics in a fun and meaningful way. Second, mathematics is based on patterns and these patterns make mathematics understandable. Third, a visual context to mathematical concepts should come before the symbolic notation. The last premise, mathematics is not memorization, but knowing basic facts comes easily with a conceptual and visual understanding. Memorization of basic mathematics facts is easy if it is based on conceptual learning and visual representations. Additionally, Shanty and Wijaya describe Math GASING as the learning process and the word arises from the capital letters of the Indonesian words that make students learning easy (Gampang), fun (ASIk), and enjoyable (menyenaNGkan) (Shanty \& Wijaya, 2012). Easy means the students are introduced to mathematical logic that is easy to learn and to remember. Exciting means the students have motivation which comes from by them to learn mathematics (intrinsic factor). Fun is more in the direction of outside influences such as visual aids and games (extrinsic factor).

Prahmana (2013) has conducted research for the division topic in Math GASING, where the learning process begins with the activities of sharing sweets fairly, then moves into the process of how each student gets distributed sweets after a fair amount of candy (concrete) is calculated, ranging from division without remainder to division with remainder, 
and ends with the completion of the division operation (abstract). Math GASING shows how to change a concrete sample into an abstract symbol so the students may read a mathematical pattern and thus gain the conclusion by themselves.

\section{Addition Operations in Math GASING}

Math GASING, as one of the innovations in learning mathematics, offers a critical point in its learning process. When studying a topic in Math GASING, there is a critical point and after reaching this critical point, students will not have difficulty anymore working on the problems in that topic (Surya, 2011). The critical point in learning addition is the addition of two numbers between 1 and 10 with a sum less than 20. In other words, when a student has mastered the addition of two numbers between 1 and 10 with a sum less than 20, the student can learn a variety of addition operation problems more easily.

The Hypothetical Learning Trajectory in this study had several learning goals expected to be reached by the students. To reach the goals formulated, researcher designs a sequence of instructional learning for learning addition in Math GASING on the following diagram (see Figure 1).

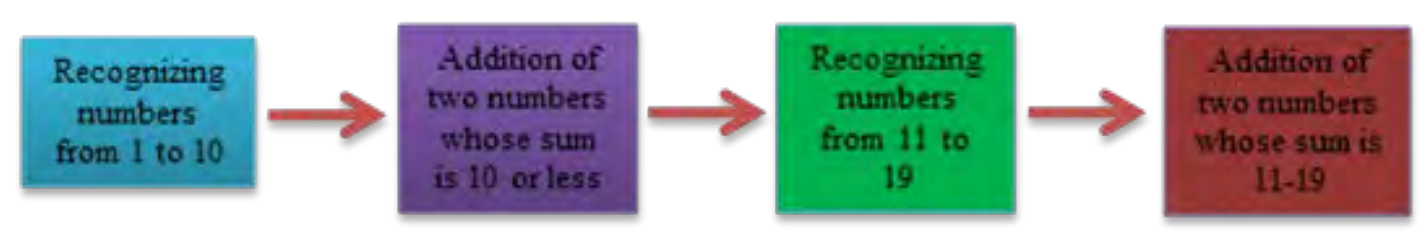

Figure 1: Hypothetical Learning Trajectory of Learning Addition in Math GASING

The explanation of Figure 1is as follows:

1. Students are recognizing numbers from 1 to 10 by using their fingers. For example, the teacher introduces the notation of number " 1 ” by showing 1 index finger or 1 thumb or 1 middle finger or 1 ring finger or 1 little finger; the notation of number "2" by showing 1 index finger and 1 thumb or 2 index fingers or 2 thumbs, and various other variations; the notation of number “ 3 ”, “ 4 ”, until “ 10 ” by using various other variations from their finger.

2. Students learn the addition of two numbers whose sum is 10 or less by using their fingers. For example, the teacher shows 3 fingers on the right hand and said "these are three fingers", and then shows 2 fingers on the left hand and said "these are two fingers". After that, she combined the fingers on both hands together and said "these are five fingers", so "three plus two is equal to five”. Lastly, students learned how to write in abstract symbols: $3+2=5$. The teacher shows all various combinations of addition from 2 to 10 . 
3. Students are recognizing numbers from 11 to 19 by using "number cards". For example, "black cards" are tens and "white cards" are units. The teacher showed 1 black card and said "this is ten", and then showed 1 white card and said "this is one". After that, she combined the two cards that consists of 1 black card and white card, and said "this is eleven”. This way the students are able to imagine that eleven consists of ten and one. The teacher shows all numbers from 11-19 by using black cards and white cards.

4. Students learn the addition of two numbers whose sum is 11-19 by using "number card". The learning process consists of some addition types namely $10^{+}, 9+, 8^{+}, 7+$, and $6+$ and starts from $10+$ type where student add the number 10 with numbers from 1 to 9 , to $6^{+}$ type (see Table 1). They also learn about the commutative law of addition according to Table 1.

Table 1.

Addition of Two Numbers Whose Sum is between 11 and 19

\begin{tabular}{ccccc}
\hline $\mathbf{1 0}+$ & $\mathbf{9 +}$ & $\mathbf{8 +}$ & $\mathbf{7 +}$ & $\mathbf{6 +}$ \\
\hline $10+1=$ & & & & \\
$10+2=$ & $9+2=$ & & & \\
$10+3=$ & $9+3=$ & $8+3=$ & & \\
$10+4=$ & $9+4=$ & $8+4=$ & $7+4=$ & \\
$10+5=$ & $9+5=$ & $8+5=$ & $7+5=$ & $6+5=$ \\
$10+6=$ & $9+6=$ & $8+6=$ & $7+6=$ & $6+6=$ \\
$10+7=$ & $9+7=$ & $8+7=$ & $7+7=$ & \\
$10+8=$ & $9+8=$ & $8+8=$ & & \\
$10+9=$ & $9+9=$ & & & \\
\hline
\end{tabular}

\section{Research Question}

Based on the brief introduction above, the researcher formulated a research question as follows: What is the student learning trajectory of learning addition in Math GASING, which evolved from informal level to formal level for rural area students at Surya College of Education?

\section{Methodology}

This study uses design research as a research methodology, which starts from preliminary design, teaching experiments, and retrospective analysis (Prahmana, Zulkardi, \& Hartono, 2012). Design research is a methodology that has five characteristics: interventionist nature; process oriented; a reflective component; a cyclic character; and theory oriented (Akker, Gravemeijer, McKenney, \& Nieveen, 2006). Design research is a cyclical process of 
thought experiment and instruction experiments (Gravemeijer, 1994). There are two important aspects related to design research. They are the Hypothetical Learning Trajectory (HLT) and Local Instruction Theory (LIT).

According to Freudenthal in Gravemeijer and Eerde (2004) students are given the opportunity to build and develop their ideas and thoughts when constructing the mathematics. Teachers can select appropriate learning activities as a basis to stimulate students to think and act when constructing the mathematics. Gravemeijer (2004) states that the HLT consists of three components, namely (1) the purpose of mathematics teaching for students, (2) learning activities, devices or media used in the learning process, and (3) a conjecture of understanding the process of learning how to learn and strategies students that arise and thrive when learning activities are done in class.

The researchers have collected data from multiple sources, to get a visualization of the students' mastery of basic concepts of addition operations, namely via video recordings, documentation (learning activities photos), and the written data (the results of students' answers and observation sheets). Furthermore, the data were analyzed retrospectively with HLT as a guide. In addition, these studies were completed in two days in the first semester of academic year 2013/2014 with the subjects being 11 matriculation prospective teacher students at Surya College of Education Tangerang and also a teaching assistant who acted as a model teacher. This study consists of three steps done repeatedly until the discovery of a new theory that a revision of the theory of learning is tested (see Figure 2).

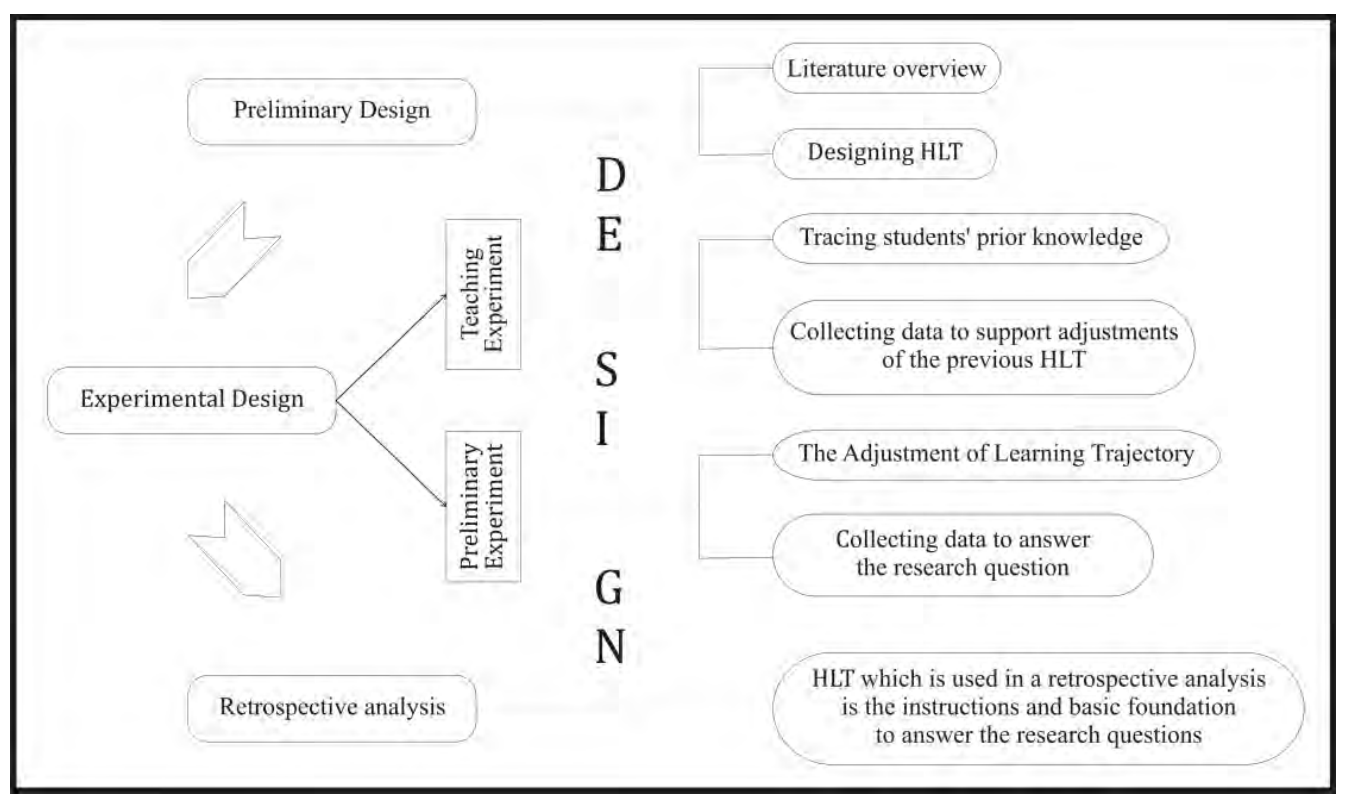

Figure 2: Phase of the Design Research (Prahmana, Zulkardi, \& Hartono, 2012) 


\section{Results}

The learning activities start from students recognizing numbers between 1 and 10 using students' fingers to introduce the concept of number in concrete levels as a sum of their fingers. Students learn the addition of two numbers whose sum is 10 or less by using their fingers. Then, students recognize numbers from 11 to 19 by using "number cards" and learning the addition of two numbers whose sum is 11-19 by using "number cards" that consist of black cards as tens and white cards as units. At the end of the second meeting, students do mental arithmetic activities namely mencongak as one of the assessment processes in these learning activities and exercises by using an student evaluation sheet. As a result, students were able to master the addition operation in Math GASING seen from the results of the final evaluation and were pleased to learn Math GASING can be seen from the comments of students who wish to abandon the old way of learning mathematics. The results of this study indicate that learning design of addition in Math GASING has a very important role as the starting point and improve students' motivation in learning addition. For more details, researchers will discuss the results of this study, which is divided into three stages that are called preliminary design, teaching experiments, and retrospective analysis.

\section{Preliminary Design}

At this stage, the researcher is beginning to implement the idea of the addition operation in Math GASING by reviewing the literature, conducting observations in the matriculation class, and designing a hypothetical learning trajectory (HLT), as shown in Figure 2. A set of activities for learning addition operation in Math GASING has been designed based on learning trajectory and the thinking process of students hypothesized. The instruction set of activities has been divided into four activities that have been completed in two meetings, starting with recognizing numbers between 1 and 10 using students' fingers as the concrete form, learning the addition of two numbers whose sum is 10 or less process by using their fingers, recognizing numbers from 11 to 19 by using "number card”, learn the addition of two numbers whose sum is 11-19 by using "number cards" that consist of black cards as tens and white cards as units, doing a variety of fun activities that make students happy in the learning process, and ending with the evaluation process.

\section{Teaching Experiment}

In the teaching experiment, the researcher tests the learning activities that have been designed in the preliminary design stage. When the teacher models have started to see 
students do not get excited, then the teacher models provide educational games that make learning activities fun, because it is one of the characteristics on Math GASING. There are four activities in this stage. First, the teacher introduces the notation of number 1 until 10 by showing her finger and student recognizes it by using their fingers as the concrete form using various other variations from their fingers (Figure 3).

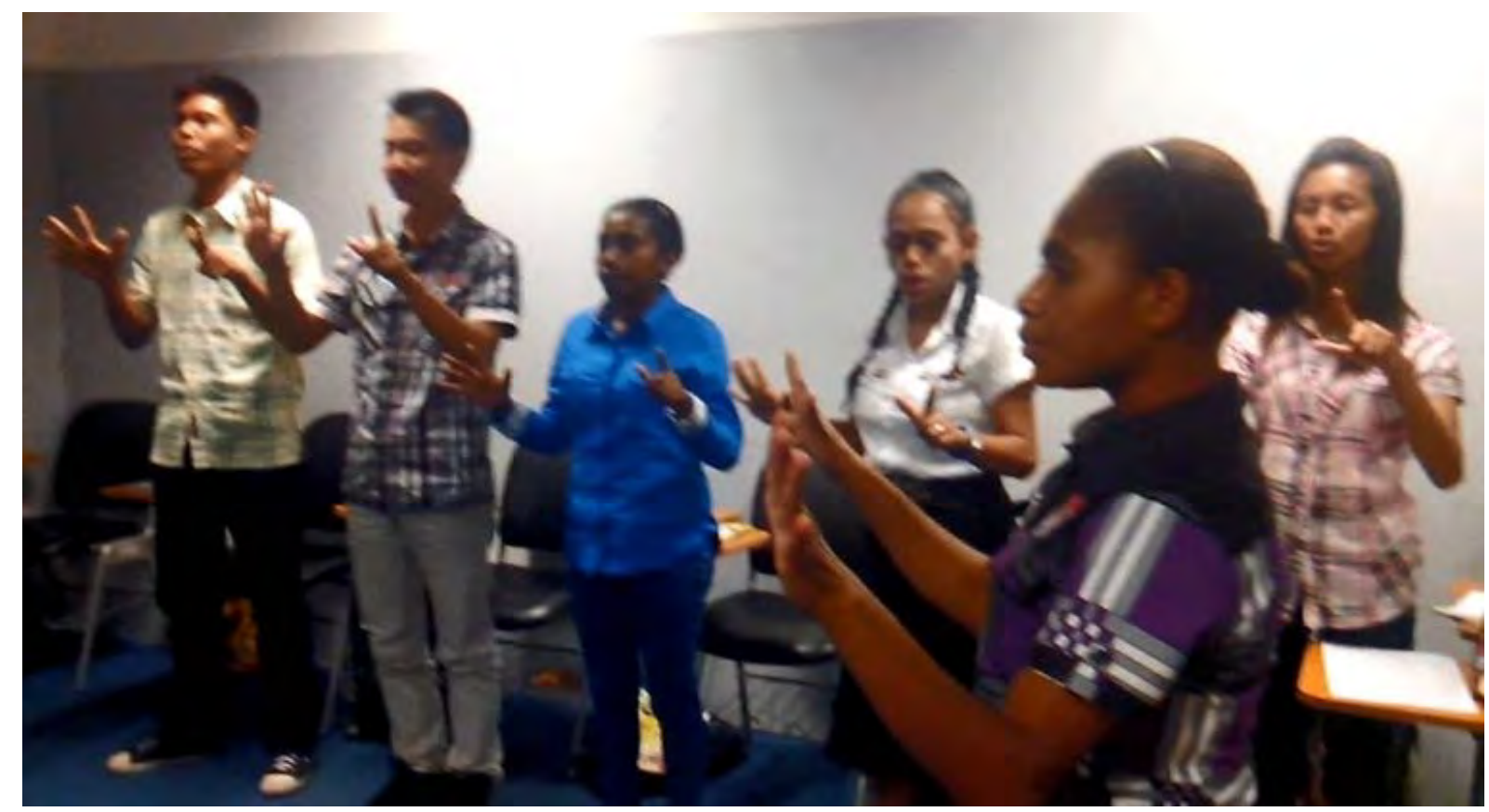

Figure 3: Students Recognize Numbers between 1 and 10 Using Their Fingers

Second, students learn the addition of two numbers whose sum is 10 or less by using their fingers. A student showed four fingers on the right hand and said "this is four", and then showed two fingers on the left hand and said "this is two". After that, she combined the fingers on both hands together and said "this is six", so "four plus two is equal to six". Lastly, students write in abstract symbols: $4+2=6$. The teacher showed all various combinations of addition from 2 to 10 (Figure 4).

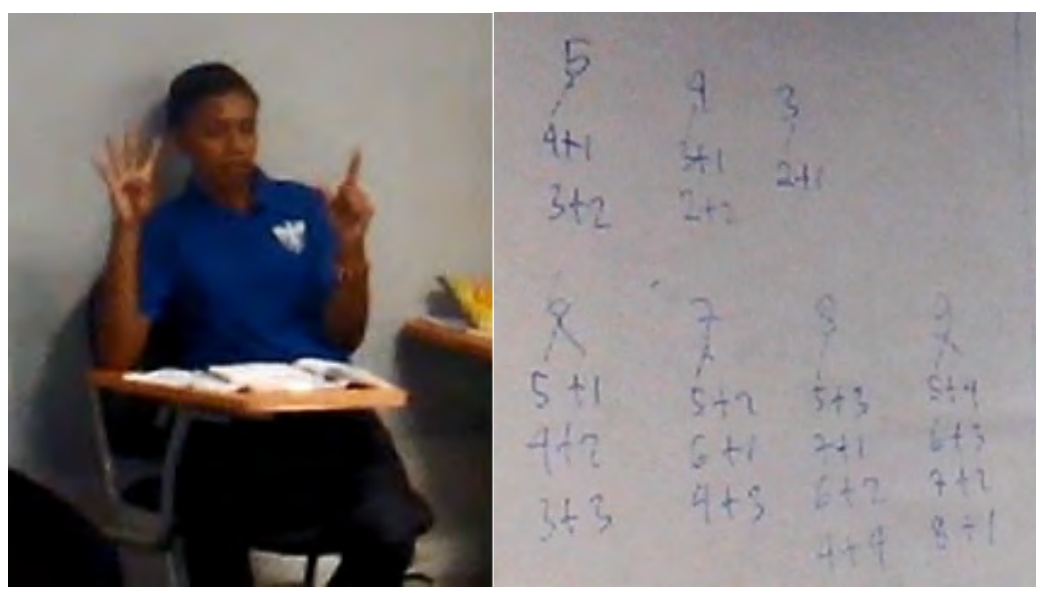

Figure 4: Students Learn Addition of Two Numbers (Left) and All Various Combinations (Right) 
Third, students are recognizing numbers from 11 to 19 by using "number cards" that consists of a "black card" as ten and a "white card" as a unit. A student showed one black card and said, "This is ten”, and then showed one white card and said, "This is one". After that, she combined the two cards of a black card and a white card, and said, "This is eleven". The teacher showed all numbers from 11-19 by using black cards and white cards (Figure 5).
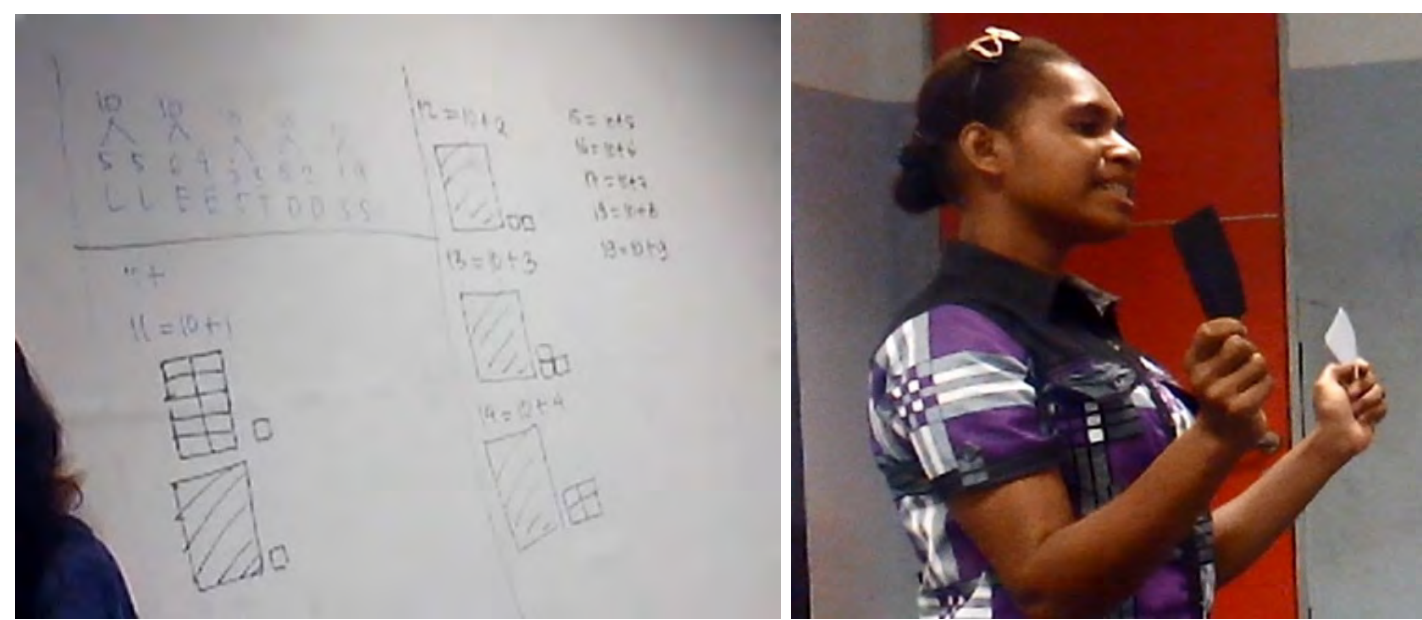

Figure 5: Concrete Form of 10+ (Left) and Students Presented the Number Card (Right)

Lastly, students learn the addition of two numbers whose sum is 11 to19 by using “number card”. The learning process consists of some addition types namely 10+, 9+, 8+, 7+, and $6+$ and starts from 10+ type where students add the number 10 with numbers from 1 to 9 , to 6+ type (Table 1). They also learn about the commutative law of addition according to Table 1. Students count nine white cards plus three white cards, and then count all white cards that she gets. After that, she switches (trades) 10 white card for one black card and now she gets one black card and two white cards, and then said, "This is twelve” (Figure 6).
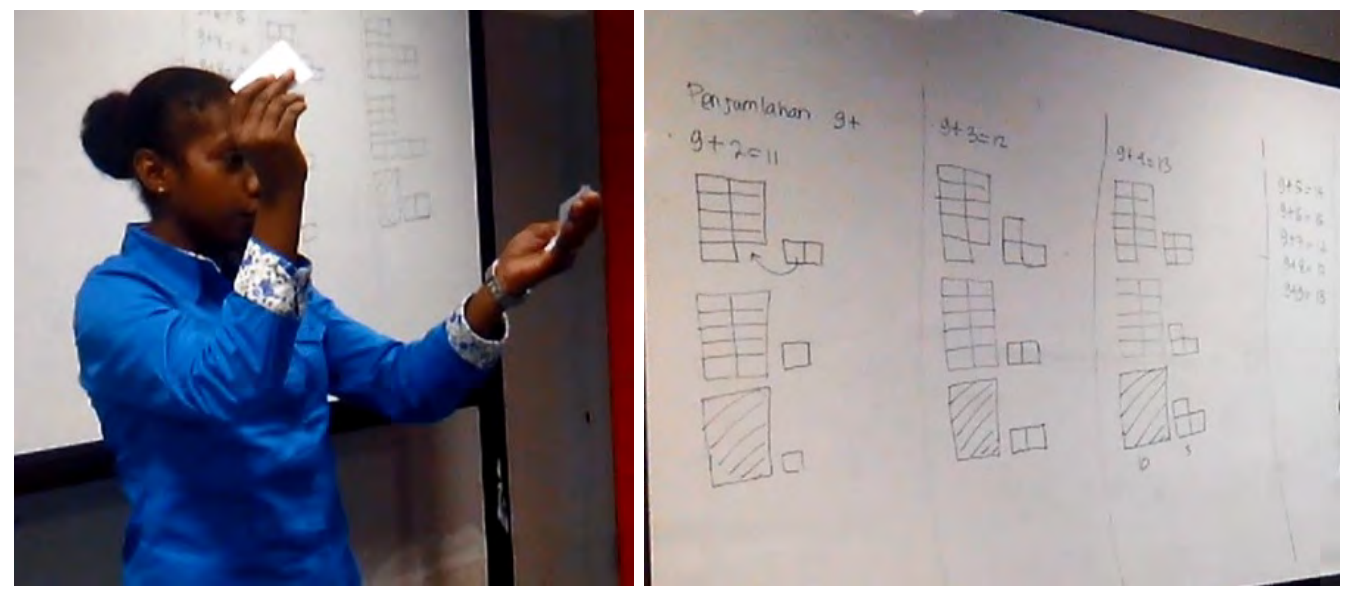

Figure 6: Students Learn Addition of Two Numbers (Left) and All Various Combinations 9+ (Right) 
The learning process in this study ends with two forms of evaluation. Firstly, students are given a spontaneous problem in front of class and answers are recorded on the whiteboard. Secondly, students are given a worksheet that consists of many questions about addition and should be able to finish it within a few minutes(Figure 7). The results of the evaluation process are quite amazing in that all students get satisfactory results and are able to explain it either concretely or abstractly.
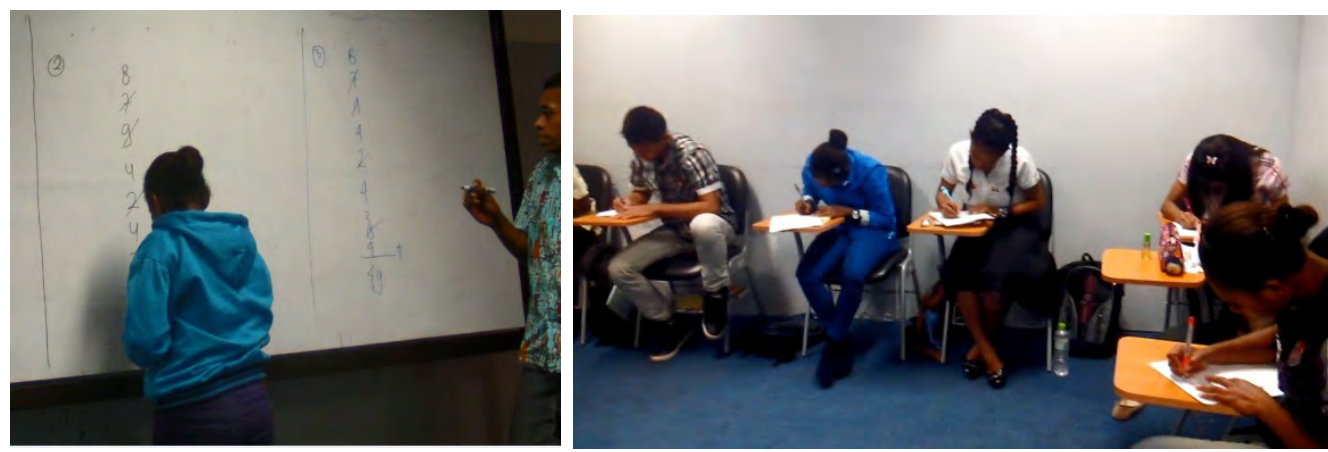

Figure 7: First Evaluation Form (Left) and the Second Evaluation Form (Right)

\section{Retrospective Analysis}

The addition process in Math GASING is different from the addition process in mathematics in general. As a result, all activities which have been designed can be used to answer the research question above. The activities are as follows:

1. The learning trajectory which has been modeled in Figure 1 are the activities undertaken in this study to guide students to master addition operation. So that, the researcher designed an activity using students' fingers to recognize numbers from 1 to 10 and to learn by using their fingers too. The goal is that students are able to imagine the concrete form of number notation between 1 and 10 and the addition of two numbers whose sum is 10 or less. Fingers are the greatest learning tool to introduce the concrete form of numbers between 1 and 10 and that addition. Next, to introduce a number greater than 10 and its sum, the researcher uses a number card starting from units, tens, hundreds, etc. by using different colors such as a white card for a unit, a black card for tens, an orange card for hundreds, etc.

2. Furthermore, from these activities, teachers guide students toward the concept of number notation and addition using their fingers and number cards. As a result, when students have mastered the addition process of two numbers whose sum is between 11 and 19, they were able to complete the various forms of addition operations more easily, using the addition process in Math GASING. So that, they can do mencongak to solve all addition 
problems given. The addition process in Math GASING starts from "front addition" where addition process is from left to right and "scratch system" for the addition of two numbers whose sum is between 10 and 19. For more details, see Figure 8.

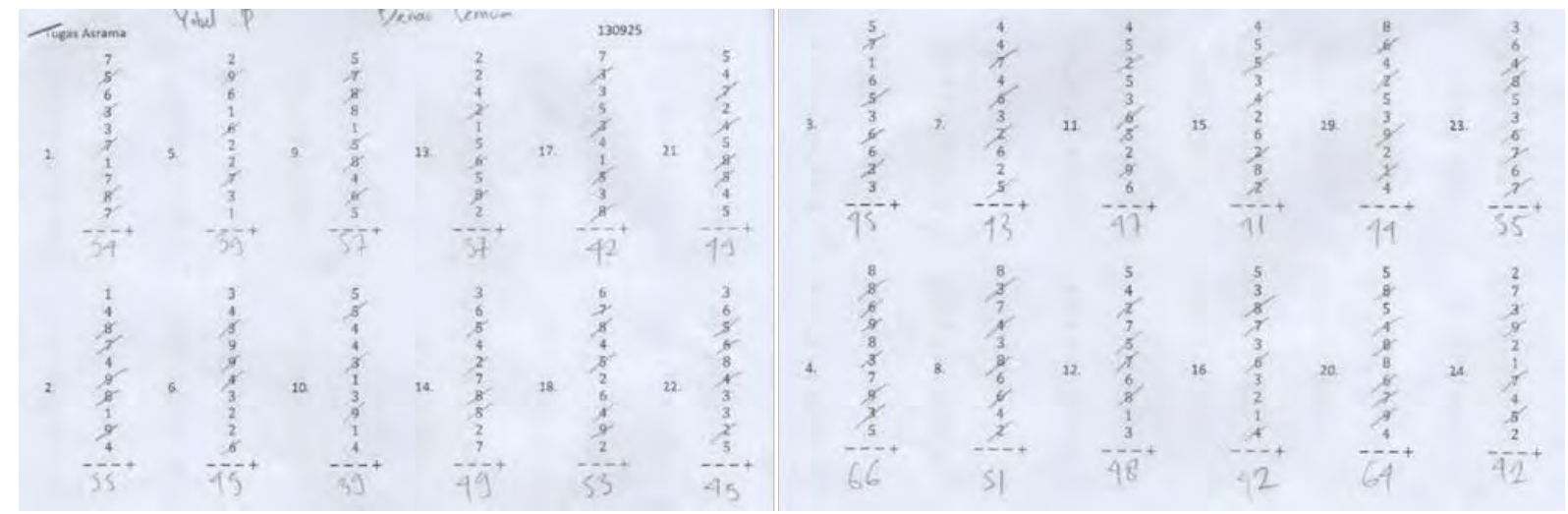

Figure 8: Student Yobel’s Answer Sheet using “Scratch System”

3. In Figure 8, Yobel's answer sheet shows the addition process in Math GASING where every addition of two numbers whose sum is more than or equal to 10 , he "scratches" on that number and so on until finished and then counts the number of scratches made and wrote it following the last number that he counted. For example, based on problem 4, $8+$ 8 is equal to 16 . It means he must scratch on " 8 ", and then $6+6$ is equal to 12 . It means he must scratch again on "6", and then $2+9$ is equal to 11 . It means he must scratch on “9”, and then $1+8$ is equal to 9 . It means he doesn't scratch on " 8 ", and continues until finished. Lastly, he got 6 scratches and "6" as the last number that he counts. So, he can write "66" as the result of that problem. On the other hand, Figure 9 shows that Rosita can solve 100 addition problems in only 7 minutes and gets one mistake using "front addition”. It is apparent that addition process in Math GASING is much more effective than the usual process of addition, when students have mastered the addition of two numbers whose sum is between 11 and 19.

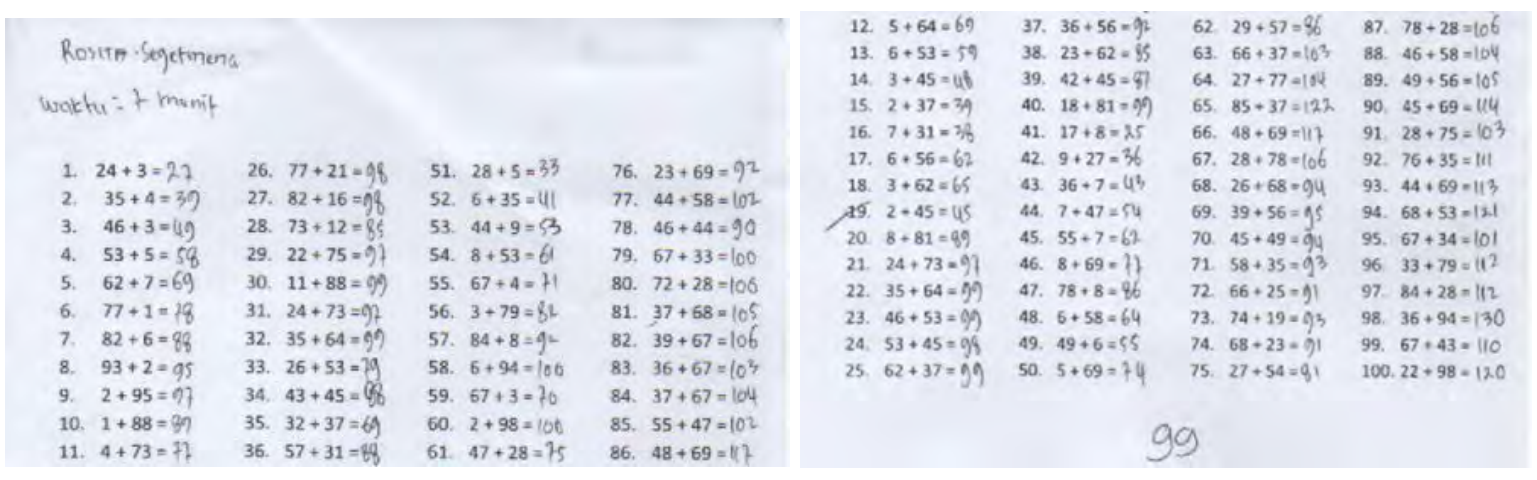

Figure 9: Rosita's answer sheet 
4. Based on all the activities above, it can be seen that the students have gone through the activity based on experience of using their fingers and "number card", moving toward the understanding of formal level from the critical point, and then reaching the formal level desired as the ultimate goal of this learning activity.

5. In the design of this study, the researcher used the learning steps of addition operation in Math GASING as shown in Figure 1. When the activity takes place, the dialogue is very good in the process of introducing the basic concepts of addition operations. In the dialogue, it seems that students feel learning addition operation in Math GASING looks so easy and so much fun. As a result, the learning process can guide students in understanding addition operations. It can also be seen from the student evaluation of learning the addition process given by the teacher to evaluate student understanding. As a result, students seemed to be able to apply addition operation process in solving each problem is given in terms of evaluation (Figure 10). Therefore, it can be seen that learning addition operation in Math GASING can be used to raise students' understanding of integer addition operations, or in other words, the design of this study can be used as the starting point of learning addition operations.

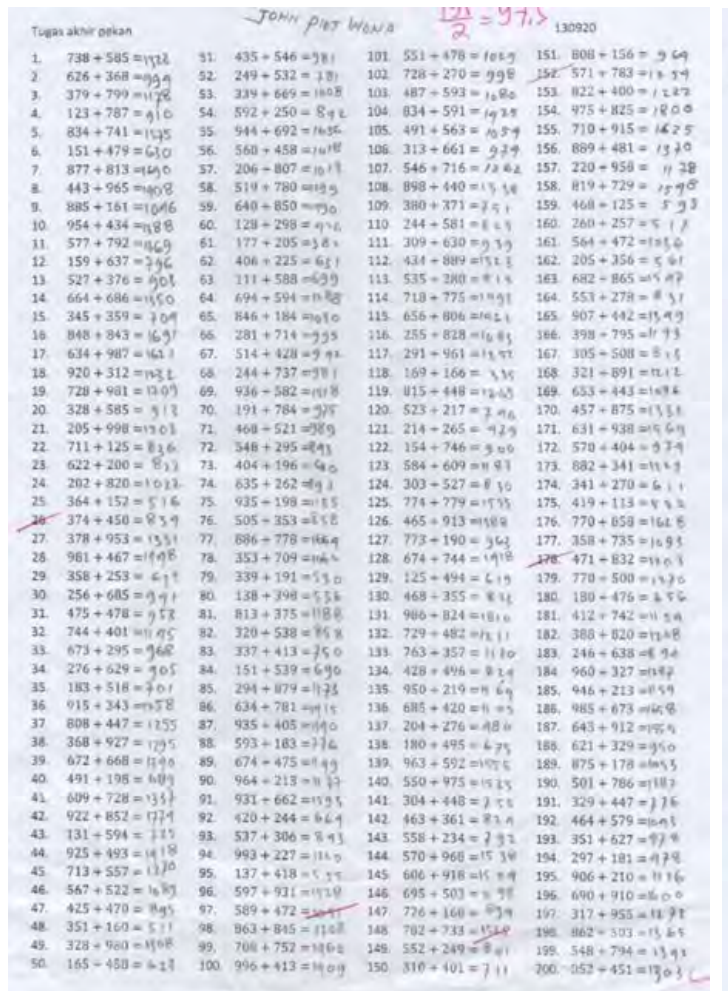

\begin{tabular}{|c|c|c|}
\hline & EXERCISE & Dotaviani. Dende. \\
\hline 1) $6+7=13$ & 44) $7+8=15$ - & $87 \mid 4+8=12$. \\
\hline 2) $5+8=130$ & $4517+7=19$ & $8836+5=11$ \\
\hline 3) $7+5=12$ & $4617+6=135$ & $8917+9=16$ \\
\hline 4) $8+4=12$ & 47) $9+7=162$ & $90) 4+7=11$ \\
\hline 5) $8+8=162$ & $48 \mid 8+8=16$ & 91) $6+8=19$ \\
\hline 6) $9+5=19$ & $49) 5+9=14$ & 92) $8+8=16$ \\
\hline $79+3=12$ & $50) 4+9=13$ & 93) $4+B=12$ \\
\hline 8) $7+8=15$ & $51 / 3+9=12$ & 94) $6+6=12$ \\
\hline 9) $6+8=19$ & $5217+8=15$ & 95) $5+9=19$. \\
\hline $1015+8=13$ & 53) $7+7=19$ & 96) $5+8=15$ \\
\hline 11) $4+9=13$ & 54) $3+8=111$ & 97) $3+8=11$ - \\
\hline 12) $9+2=11$ & 55) $3+9=12$ & 98) $2+9=11-$ \\
\hline $1317+7=19$ & $56) 7+8=15$ & 99) $9+6=15$ \\
\hline $1417+9=16$ & $5717+7=19$ & 100) $5+9=-14$ \\
\hline 15$) 8+5=13$ & $58) 6+7=\frac{13}{3}$ & \\
\hline 16) $4+9=\frac{13}{4}$ & 59) $6+8=\frac{14}{19}$ & \\
\hline $1715+8=13$ & $6015+8=13$ & \\
\hline $1817+8=\frac{15}{15}$ & $6115+6=11$ & (waktu: 5 menit) \\
\hline 19) $3+9=12$ & $6215+8=\frac{13}{3}$ & \\
\hline 20) $5+9=19$ & 63) $5+9=\frac{19}{4}$ & \\
\hline 21) $9+2=\frac{11}{14}$ & 54) $6+9=15$ & \\
\hline $2219+5=19$ & $6517+9=16$ & \\
\hline $2317+6=13$ & $6616+7=15$ & \\
\hline 24) $4+8=12$ & $67 / 4+7=11$ & \\
\hline $2515+7=\frac{12}{2}$ & $68 / 3+9=12$ & \\
\hline $2616+9=15$ & 69) $7+7=19$ & \\
\hline $2715+7=12$ & $7016+7=13$ & 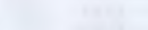 \\
\hline $2815+9=19$ & $7116+8=14$ & \\
\hline $2915+7=n$ & $7217+9=16$ & 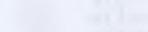 \\
\hline $3016+9=15$ & 73) $9+6=15$ & \\
\hline 31) $4+8=\frac{12}{12}$ & $74) 8+9=12$ & \\
\hline 32) $3+8=11$ & $7514+7=110$ & \\
\hline 33$) 4+9=13$ & $7619+6=15$ & \\
\hline 34) $4+8=12$ & $7714+8=\overline{12}$ & \\
\hline 35) $5+6=\frac{11}{11}$ & $7817+6=13$ & \\
\hline 36) $6+8=19$ & $79) 7+5=12$ & \\
\hline 37) $4+8=12-$ & $80) 5+7=\frac{12}{12}$ & \\
\hline 38$) 5+7=12$ & $81) 4+9=13$ & \\
\hline 39) $5+9=14$ & $82) 3+9=12$ & \\
\hline 40) $9+8=17$ & 83) $7+6=\frac{13}{13}$ & \\
\hline 41) $7+8=\frac{15}{12}$ & 84) $7+9=16$ & \\
\hline $4218+9=17$ & 85) $2+9=11$ & \\
\hline $4314+7=11$ & $8618+9=17$ & \\
\hline
\end{tabular}

Figure 10: Some Students’Answer Sheets 


\section{Conclusion}

Based on the result of this research described above, the researcher can conclude that the learning of addition operation in Math GASING has a very important role as a starting point and improves students' motivation in the process. In addition, the activities have been designed in such way that students discover the concept of addition operation in a fun and easy process.

\section{Acknowledgement.}

The researchers would like to thank Petra Suwasti and Samsul Arifin for their contribution in order to collect data and to be a model teacher and research assistant in this research. 


\section{References}

Akker, J.V.D., Gravemeijer, K., McKenney, S., \& Nieveen, N. (2006). Education Design Research. London: Routledge Taylor and Francis Group.

Arganbright, D. (2007). Spreadsheets in Mathematics: Accessibility, Creative, and Fun. The Electronic of Journal of Mathematics and Technology , 1(3), 212-231.

Carpenter, T., \& Fennema, E. (1992). Cognitively Guided Instruction: Building on the knowledge of students and teachers. Curriculum reform: The case of mathematics in the United States. Special issie of the International Journal of Educational Research , 457470.

Gravemeijer, K. (1994). Developing Realistic Mathematics Education. Culemborg: Utrecht: Technipress.

Gravemeijer, K. (2004). Local Instructional Theories as Means of Support for Teacher in Reform Mathematics Education. Mathematical Thinking and Learning , 6(2), 105-128.

Gravmeijer, K., \& Eerde, D.V. (2004). Design Research as a Means for Building a Knowledge Base for Teaching in Mathematics Education . The Elementary School Journal , 109 (5).

National Council of teachers of Mathematics ( NCTM). (2000). Principles and Standards for School Mathematics. Reston: National Council of Teachers of Mathematics.

Ornstein, A., Levine, D., \& Gutek, G. (2011). Foundations of Education (11 ed.). Belmont: Wadsworth.

Prahmana, R. (2013). Designing Division Operation Learning in The Mathematics of Gasing. Proceeding in The First South East Asia Design/ Development Reasearch ( SEA-DR) Conference (pp. 391-398). Palembang: Sriwijaya University.

Prahmana, R., Zulkardi, \& Hartono, Y. (2012). Learning Multiplication Using Indonesian Traditional Game in Third Grade. IndoMS-Journal on Mathematics Education (IndoMSJME) , 3(2), 115-132.

Reys, R., Suydam, M., Lindquist, M., \& Smith, N. (1984). Helping Children Learn Mathematics (5 ed.). Boston: Allyn and Bacon.

Shanty, N., \& Wijaya, S. (2012). Rectangular Array Model Supporting Students' Spatial Structuring in Learning Multiplication. Indo-MS-Journal on Mathematics Education (IndoMS-JME) , 3(2), 175-186.

Surya, Y. (2011). Petunjuk Guru: Dasar-Dasar Pintar Berhitung GASING. Tangerang: PT. Kandel.

Surya, Y., \& Moss, M. (2012). Mathematics Education in Rural Indonesia. 12th

International Congress on Mathematics Education: Topic Study Group 30 (pp. 6223-6229).

Seoul: Korea National University of Education. 